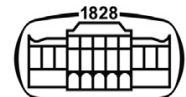

AKADÉMIAI KIADÓ

Acta Chromatographica

33 (2021) 2, 120-126

DOl:

10.1556/1326.2020.00769

(C) 2020 The Author(s)

ORIGINAL RESEARCH PAPER

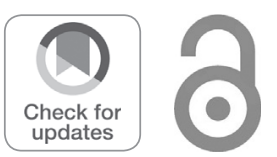

\section{Bioanalytical method validation of Esomeprazole by high performance liquid chromatography with PDA detection}

\author{
FATEMA MONI, SURIYA SHARMIN, SATYAJIT ROY RONY, \\ FARHANA AFROZ, SHAMMI AKHTER and \\ MD. HOSSAIN SOHRAB* ${ }^{*}$
}

Pharmaceutical Sciences Research Division, BCSIR Laboratories Dhaka, Bangladesh Council of Scientific and Industrial Research (BCSIR), Dhaka, 1205, Bangladesh

Received: January 29, 2020 - Accepted: March 21, 2020

Published online: May 21, 2020

\begin{abstract}
This study describes the development and validation of a simple, specific, accurate, and precise method for quantitative determination of Esomeprazole in human serum using Pantoprazole as internal standard (IS). After the addition of internal standard, Esomeprazole from serum samples was extracted simply by protein precipitation method followed by centrifugation and the supernatants were directly injected into the high performance liquid chromatography (HPLC). The chromatographic separation of the compounds was obtained on Hitachi Lachrom C8 column $(5 \mu \mathrm{m}, 250 \times 4.6 \mathrm{~mm})$ with a mobile phase consisting of $5 \mathrm{mM}$ potassium dihydrogen phosphate $\mathrm{pH} 7.4$ and acetonitrile in a ratio of 70:30 with UV detection at $302 \mathrm{~nm}$ with a flow rate of $1 \mathrm{~mL} / \mathrm{min}$. The method was sensitive and specific, and validated over a concentration range of $0.06-6.0 \mu \mathrm{g} / \mathrm{mL}$. The limit of detection (LOD) and lower limit of quantification (LOQ) was 0.03 $\mu \mathrm{g} / \mathrm{mL}$ and $0.06 \mu \mathrm{g} / \mathrm{mL}$, respectively. The precision and accuracy expressed as relative standard deviation were less than $15 \%$. The average recovery of Esomeprazole from serum was $97.08 \%$.
\end{abstract}

\section{KEYWORDS}

bioanalytical method validation, Esomeprazole, Pantoprazole, HPLC

\section{INTRODUCTION}

Esomeprazole, the S-isomer of Omeprazole (Fig. 1) belongs to the class of medications known as proton pump inhibitor (PPI) which suppresses the secretion of hydrochloric acid from gastric parietal cells via inhibition of the $\mathrm{H}+/ \mathrm{K}+$ ATPase (adenosine triphosphatase) enzyme $[1,2]$.

Studies have shown that a decrease in the amount of gastric acid produced was beneficial for patients with erosive esophagitis, symptomatic gastro esophageal reflux disease (GERD), NSAID-associated gastric ulcers, Helicobacter pylori (H. pylori) infections, and ZollingerEllison syndrome. Proton pump inhibitors (PPIs) have been shown to relieve patients with GERD symptoms. Among all proton pump inhibitors available, Esomeprazole is the first to demonstrate significantly greater healing rates than Omeprazole in the treatment of patients with erosive esophagitis $[3,4]$. Esomeprazole is eliminated less rapidly than R-omeprazole, which theoretically provided a therapeutic advantage because of the increased half-life [5].

Esomeprazole is absorbed rapidly after oral administration. In two studies, with a total of 32 healthy volunteers, the peak serum concentration of Esomeprazole $\left(C_{\max }\right)$ was found to be within $0.5 \mathrm{~h}$ of ingestion of an oral solution containing $20 \mathrm{mg}$ and within $1-3.5 \mathrm{~h}$ for encapsulated enteric-coated granules $\left(40 \mathrm{mg}\right.$ ) [6]. The $C_{\max }$ increases proportionally when the dose is increased and higher $C_{\max }$ was also observed after repeated dosing of Esomeprazole. It was reflected by a $43 \%$ increase of $C_{\max }(1.90 \mu \mathrm{mol} / \mathrm{L}$ versus $2.6 \mu \mathrm{mol} / \mathrm{L})$ and a $90 \%$ 


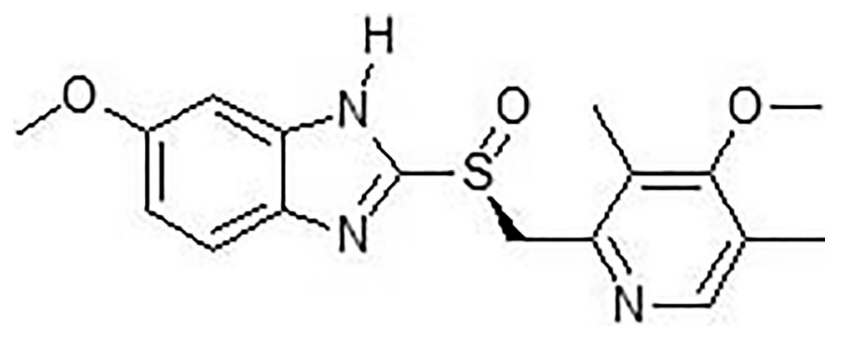

Fig. 1. Chemical structure of Esomeprazole

increase of AUC $(1.34 \mu \mathrm{mol} \times \mathrm{h} / \mathrm{L}$ versus $2.55 \mu \mathrm{mol} \times \mathrm{h} / \mathrm{L})$ after repeated dosing of $20 \mathrm{mg}$ Esomeprazole (once daily) for five days after a single dose. Absolute bioavailability was found to be $50 \%$ on day 1 and $68 \%$ on day 5 . Similarly, after $40 \mathrm{mg}$ oral administration, peak plasma concentration was increased by $95 \%(2.38 \mu \mathrm{mol} / \mathrm{L}$ versus $4.64 \mu \mathrm{mol} / \mathrm{L})$ and the AUC by $159 \%(4.32 \mu \mathrm{mol} \times \mathrm{h} / \mathrm{L}$ versus $11.21 \mu \mathrm{mol} \times \mathrm{h} / \mathrm{L})$ after repeated dosing (on day 5) compared with single dose (on day 1 ); while absolute bioavailability was found to be $64 \%$ on day 1 and $89 \%$ on day 5 [1]. Increase in systemic exposure, after single oral administration of Esomeprazole, is dose-related and has shown a nonlinear increasing fashion [6].

New drug development is a series of activities including lead optimization/selection, confirmation and testing process, pharmacokinetic study, etc., which demand development of different bioanalytical methods to provide information for effective decision making. A synergistic relationship exists between the development of bioanalytical technology and the application to pharmacokinetic (pk) study that plays a vital role in new and generic drug development.

According to Food and Drug Administration (FDA), the bioanalytical methods should be developed following standard regulatory guidelines and the measurement method of analyte in the biological matrix using a sophisticated instrument need to be validated to give reliable and reproducible data [7].

High performance liquid chromatography (HPLC) and HPLC-MS/MS are the widely used methods to quantify Esomeprazole in biological fluids [8-11]. As development of analytical method is evolving through technological platform, it is a never ending process. As an effort to develop a simple method, our laboratory is continually investigating the applications of HPLC and LC-MS/MS in biological analysis. The main aim of the present study was to develop a simple, accurate, and precise method for determination of Esomeprazole in human serum using HPLC suitable for Pharmacokinetic study, Bioavailability, and Bioequivalence study.

\section{EXPERIMENTAL}

\section{Chemicals}

Esomeprazole and Pantoprazole (Internal standard, IS) were kindly provided by Beximco Pharmaceuticals Ltd., Bangladesh. Acetonitrile was HPLC grade and purchased from Active fine Chemicals, Bangladesh. Potassium dihydrogen phosphate and potassium hydroxide were purchased from Merck, Germany. Other chemicals were all of analytical grade. A MILI-Q ${ }^{\circledR}$ (Milipore, France) water purification system was used to obtain the purified water for analysis.

\section{Instrumentation and chromatographic system}

The separation was performed on the HPLC system (Hitachi Chromaster) consisted of an LC pump (Chromaster 5110 pump), a column oven (Chromaster 5310 Column Oven), a photo diode array detector (Chromaster 5430 Diode Array Detector), an autosampler (Chromaster 5210 autosampler with thermostat) coupled to a personal computer running the software Open Lab for data acquisition.

The mobile phase used here is an optimized mobile phase [2] consists of potassium dihydrogen phosphate, 5 $\mathrm{mM}(\mathrm{pH} 7.4$ ) and acetonitile in the ratio of 70:30. The $\mathrm{pH}$ of phosphate buffer was adjusted with $30 \%$ potassium hydroxide solution.

The separation was achieved at ambient temperature $\left(25^{\circ} \mathrm{C}\right)$ using a Hitachi Lachrom C8 column $(5 \mu \mathrm{m}, 250 \times$ $4.6 \mathrm{~mm}$ ) fitted with a Hitachi guard C8 column $(5 \mu \mathrm{m}, 23 \times$ $4 \mathrm{~mm}$ ). The flow rate was set at $1 \mathrm{~mL} / \mathrm{min}$ and the detector was configured with a discrete channel at $302 \mathrm{~nm}$. Sample was injected using an autosampler, and the injection volume was $20 \mu \mathrm{L}$.

System suitability test is a critical component of bioanalysis that monitors the instrument performance throughout the run while using liquid chromatography. After obtaining the optimum conditions for analysis of Esomeprazole, the solution of Esomeprazole was injected along with internal standard with six replicate injections. System suitability data was measured in terms of CV (coefficient of variation), peak asymmetry, peak purity, and theoretical plate number.

\section{Preparation of primary stock solution}

To prepare standards and quality control (QC) solutions, a stock solution of Esomeprazole at the concentration of 100 $\mu \mathrm{g} / \mathrm{mL}$ was prepared in mobile phase with accurate weighing. The stock solutions were prepared in mobile phase in amber colored volumetric flask because Esomeprazole is light sensitive. The stock solution of IS was prepared by dissolving $10.0 \mathrm{mg}$ of Pantoprazole in $100 \mathrm{~mL}$ of mobile phase and further diluted to make the final concentration of $3 \mu \mathrm{g} / \mathrm{mL}$. Working solutions of Esomeprazole and Pantoprazole were stored in $4{ }^{\circ} \mathrm{C}$. These solutions were stable for 10 days.

\section{Preparation of serum sample for calibration curve and quality control solutions}

Human serum was obtained from healthy volunteers after obtaining approval from National Research Ethics Committee. After collection of blood sample it was allowed to stand for $30 \mathrm{~min}$ and centrifuged to obtain serum sample. The serum was stored in freezer at $-20{ }^{\circ} \mathrm{C}$ for further use. 
To prepare a calibration curve, a series of standard solutions of Esomeprazole were prepared by serial dilution of primary stock solution in mobile phase to achieve the final concentration of $0.6,1.50,3.00,15.00,30.00$, and $60.00 \mu \mathrm{g} /$ $\mathrm{mL}$. Calibration standards were prepared by spiking $50 \mu \mathrm{L}$ of Esomeoprazole from each dilution to $450 \mu \mathrm{L}$ of blank serum to produce a calibration curve point equivalent to $0.06,0.15$, $0.30,1.5,3.0$, and $6.0 \mu \mathrm{g} / \mathrm{mL}$. $25 \mu \mathrm{L}$ of Pantoprazole (Internal Standard) was added to the serum before extraction.

A blank sample (a serum sample processed without IS and Esomeprazole), a zero sample (a serum processed with IS) and six non-zero samples covering the range 0.06-6.0 $\mu \mathrm{g} / \mathrm{mL}$ was run to construct calibration curve. Ratio of peak area of Esomeprazole to Pantoprazole as a function of concentration of Esomeprazole was plotted to construct calibration curve. Quality control (QC) samples were prepared at four different levels, like lower limit of quantification (LLOQ) $(0.06 \mu \mathrm{g} / \mathrm{mL})$, low $(0.24 \mu \mathrm{g} / \mathrm{mL})$, medium $(2.4$ $\mu \mathrm{g} / \mathrm{mL})$, and high $(4.8 \mu \mathrm{g} / \mathrm{mL})$. Following the same process mentioned above the QC samples were prepared using a different stock solution of Esomeprazole to obtain serum concentration of $0.06,0.24,2.4$, and $4.80 \mu \mathrm{g} / \mathrm{mL}$. All the samples were stored at $-20{ }^{\circ} \mathrm{C}$.

\section{Extraction procedure}

All of QC, calibration curve samples were extracted employing a protein precipitation extraction technique. Samples of spiked serum with Esomeprazole $(500 \mu \mathrm{L})$ were transferred to $2 \mathrm{~mL}$ Eppendorff tubes and added $25 \mu \mathrm{L}$ of Pantoprazole and the protein was precipitated with 0.975 $\mathrm{mL}$ of Acetonitrile. The Eppendorff tubes were vortexed and then centrifuged for $12 \mathrm{~min}$ at $12,000 \mathrm{rpm}$. The supernatant was collected, transferred to autosampler vials and directly injected into HPLC.

\section{Method validation}

The rationale of analytical method development is to provide consistent, reliable, and accurate data. For this reason, the performances and the limitations of the method, as well as the external influences which may modify these features, must be determined prior to its use. Validation plays a major role in achieving this goal.

The method validation assays were carried out according to the US Food and Drug Administration (FDA) bioanalytical method validation guidance [7]. The following parameters were considered:

Specificity. Specificity studies were performed to evaluate the degree of interference during HPLC injection. It is also known as selectivity. The method's specificity was tested by screening six different batches of healthy human blank serum. Each blank sample was tested for interference using the proposed extraction procedure and chromatographic/ spectroscopic conditions, and compared with those obtained with a serum spiked solution of the analytes at a concentration to the lower limit of quantification. Selectivity is the ability of the bioanalytical method to measure unequivocally and to differentiate the analyte(s) in the presence of components which may be expected to be present. Typically, these might include metabolites, impurities, degradants, matrix components, etc.

Sensitivity. Sensitivity of the method was determined in terms of LLOQ. The LLOQ is the lowest amount of analyte in a sample that can be quantitatively determined with suitable accuracy (percent error $<20 \%$ ) and precision (coefficient of variation $<20 \%$ ). The analyte response at the LLOQ level should be at least five times greater than the analyte response of the zero calibrator. The lower limit of detection (LOD) was the minimum concentration that can be detected by detector response with analyte response should be equal to or greater than three times of the analyte response of the zero calibrator. LLOQ was measured by five replicate analyses of the analyte.

Recovery and matrix effect. The extraction yield was determined by comparing the Esomeprazole/IS peak area ratios of directly injected standard in the mobile phase and those from drug-free serum spiked with standards and submitted to the sample preparation and extraction procedures. This procedure was repeated for the four different concentrations of Esomeprazole added such as 0.06, 0.24, 2.4 , and $4.8 \mu \mathrm{g} / \mathrm{mL}$ of serum concentration with five replicate analyses of every concentration.

Linearity. The relationship of the sample concentration with corresponding detector response (peak area and height, here ratio of peak area of Esomeprazole to Pantoprazole) was used for the linearity study [12]. Linearity was tested for the range of concentrations of $0.06-6.0 \mu \mathrm{g} / \mathrm{mL}$. For the determination of linearity, standard calibration curves of at six points (non-zero standards) were used. In addition, a blank serum sample was also analyzed to confirm the absence of interferences; this sample was not used to construct the calibration function. The acceptance criterion for correlation coefficient was 0.99 or more, otherwise the calibration curve would be rejected. Three replicate analyses were done for each concentration.

Precision and accuracy. Accuracy together with precision is a vital parameter to determine the error associated with an analytical method for the evaluation of the suitability of an analytical method for intended use [13]. To determine the precision of the assay, the QC serum samples by replicate analysis of four concentration levels of Esomeprazole were used $(0.06,0.24,2.40$, and $4.80 \mu \mathrm{g} / \mathrm{mL})$. Intra-day precision and accuracy were determined by repeated analysis of the group of standards on one day $(n=5)$. Inter-day precision and accuracy were determined by repeated analysis on three consecutive days ( $n=5$ per day). The concentration of each sample was determined using a standard curve prepared and analyzed on the same day.

Stability studies. Ensuring analyte stability in biological sample is a crucial part in the application of any quantitative bioanalytical method. Stability study should be conducted in 
the actual matrix though suitable surrogate matrices can be used in case of rare matrices. Four QC samples were analyzed for stability study and five replicate analyses were done for each concentration of analyte.

Short-term temperature stability. Serum samples were stored for $48 \mathrm{~h}$ at $-20{ }^{\circ} \mathrm{C}$ to study the short-term stability. Samples were analyzed after extraction with acetonitrile following the method mentioned previously. Four QC samples were analyzed for short-term stability.

Long-term temperature stability. Long-term stability of Esomeprazole in human serum was studied after storage of serum sample for a period of 15 days employing at four different concentration levels of QC samples. If the analyte was found to be unstable at $-20{ }^{\circ} \mathrm{C}$, after the stability study, then it would be stored at $-70{ }^{\circ} \mathrm{C}$.

Freeze and thaw stability. QC serum samples containing Esomeprazole were tested after three freeze $\left(-20{ }^{\circ} \mathrm{C}\right)$ and thaw (room temperature) cycles.
Post-preparative stability. The post-preparative/autosampler stability should be monitored to ensure the sample stability during HPLC run. Post-preparative stability was conducted by reanalyzing the extracted QC samples kept under autosampler conditions $\left(25^{\circ} \mathrm{C}\right)$ for $24 \mathrm{~h}$.

\section{RESULT AND DISCUSSION}

\section{Sample preparation}

Protein precipitation method is a faster and easier process for plasma/serum sample preparation than other extraction processes like liquid-liquid extraction, solid-phase extraction technique. etc., though direct injection of plasma samples after precipitation of protein is reported to have disadvantages such as low recovery due to drug co-precipitation, unavoidable dilution of the sample as well as increased column back pressure [14]. Acetonitrile, trichloroacetic acid (TCA) and zinc sulfate were reported to be better than other protein precipitating agents for removing protein from plasma about 96, 92, and 91\%, respectively, at 2:1 ratio of precipitant to plasma [15]. In

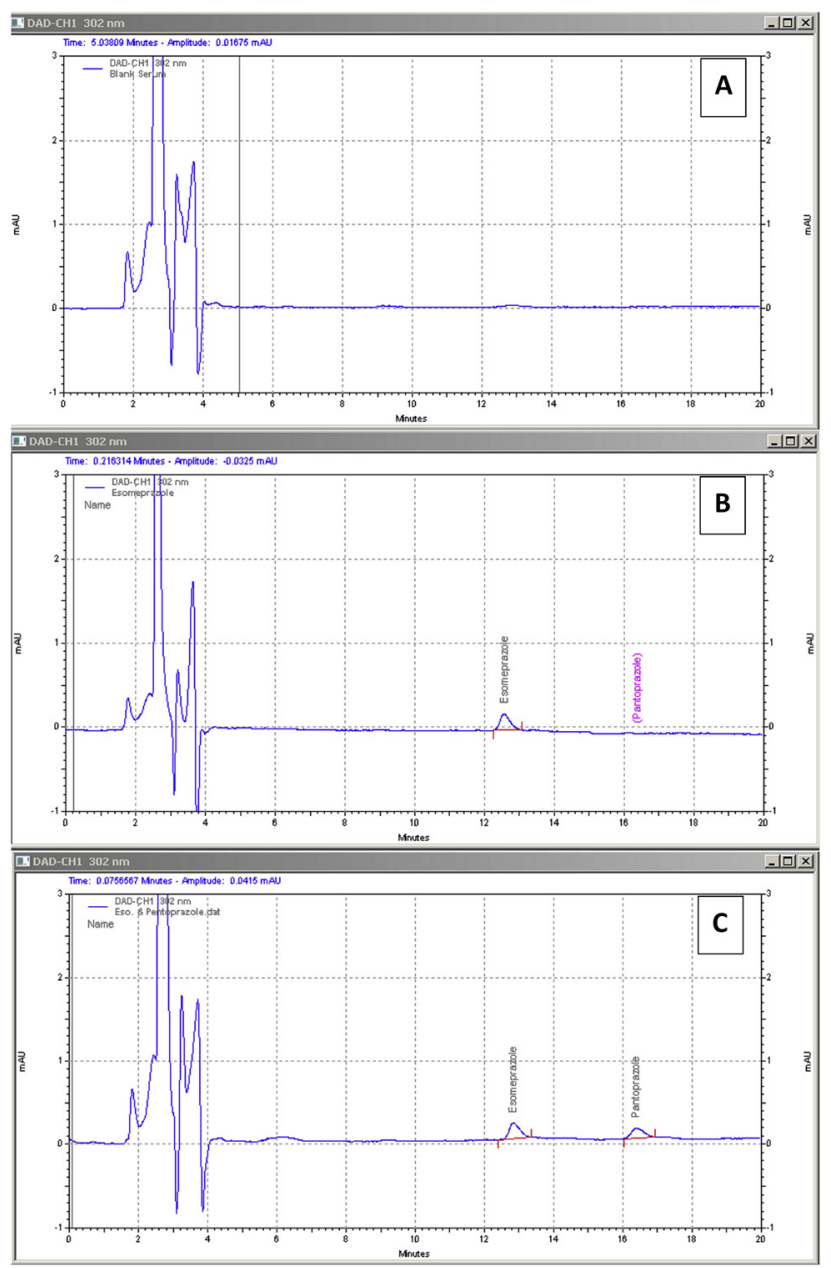

Fig. 2. A representative chromatogram for selectivity test (A) blank serum, (B) serum spiked with Esomeprazole at LLOQ and (C) serum spiked with Esomeprazole at LLOQ and Pantoprazole (IS) 
our study, acetonitrile was used for protein precipitation at a ratio of 1:2 (serum:acetonitrile). It was found that centrifugation rate is a key parameter to be controlled, with lower centrifugation rate less than $4,000 \mathrm{rpm}$ resulted a peak tailing only after 25-30 injections due to incomplete precipitation of the protein into the pellet at the bottom of the Eppendorff tube [14]. Centrifugation rate greater than $10,000 \mathrm{rpm}$ for at least $10 \mathrm{~min}$ had helped a lot to solve the problem.

\section{Method validation}

Selectivity and chromatography. The selectivity of the method was investigated by comparing the chromatograms of a blank serum, volunteer's serum sample spiked with internal standard and Esomeprazole. The method was found to be specific and selective. The retention times were 12-13 min and 15-16 min for Esomeprazole and Pantoprazole, respectively. As shown in Fig. 2, there were no interfering peaks from endogenous substances at the elution time of Esomeprazole and Pantoprazole. Selectivity was further verified by performing peak purity analysis which was found to be 0.9654 and 0.9065 for Esomeprazole and Pantoprazole, respectively. To ensure the instrument performance, other system suitability parameters such as peak asymmetry, theoretical plate number were also monitored and found to be 1.11 and 1.10; 17,580, and 16,447 for Esomeprazole and Pantoprazole, respectively. After replicate injection of analyte \%RSD was found to be less than $2 \%$.

Sensitivity. The LLOQ was found to be $0.06 \mu \mathrm{g} / \mathrm{mL}$ with accepted accuracy (percent error $<20 \%$ ) and precision (coefficient of variation $<20 \%$ ). Fig. 2 shows the chromatogram that contained $0.06 \mu \mathrm{g} / \mathrm{mL}$ (LLOQ) of Esomeprazole. The analyte response at the LLOQ was $317 \mu \mathrm{V}$ and the response of the zero calibrator/blank was $29 \mu \mathrm{V}$. So the ratio of
Table 1. Recovery of Esomeprazole from serum $(n=5)$

\begin{tabular}{lcc}
\hline $\begin{array}{l}\text { Added concentration } \\
(\mu \mathrm{g} / \mathrm{mL})\end{array}$ & $\begin{array}{c}\text { \% Recovery } \\
(\text { mean } \pm \mathrm{SD})\end{array}$ & $\begin{array}{c}\text { RSD } \\
(\%)\end{array}$ \\
\hline 0.06 & $95.20 \pm 9.50$ & 9.98 \\
0.24 & $97.23 \pm 3.73$ & 3.81 \\
2.40 & $96.30 \pm 5.54$ & 5.71 \\
4.80 & $99.57 \pm 5.93$ & 5.93 \\
\hline
\end{tabular}

analyte response to zero calibrator was 10.93 , which was within acceptable limit. The LOD was found to be $0.03 \mu \mathrm{g} /$ $\mathrm{mL}$ with analyte response to zero calibrator ratio greater than 3.

Recovery and matrix effect. The extraction recoveries of Esomeprazole were determined at four different concentrations $(0.08,0.24,2.40$, and $4.80 \mu \mathrm{g} / \mathrm{mL})$. The method showed good efficiency in terms of recovery as the average recovery for Esomeprazoe ranges from 95.20 to $99.50 \%$ (Table 1). The recovery of Pantoprazole was consistent and precise. Extraction method was simple and faster as there is no drying step present in sample preparation process.

Linearity, accuracy and precision. The method shows linearity over the concentration range of $0.06-6.0 \mu \mathrm{g} / \mathrm{mL}$ (Fig. 3), with a coefficient of correlation $\left(R^{2}\right)=0.9986$. The intra-day precision (expressed as the \%CV for QC samples of $0.08,0.24,2.40$, and $4.80 \mu \mathrm{g} / \mathrm{mL}$ ) was in the range of $3.80-7.16 \%$ and inter-day precision was $0.25-5.66 \%$. The accuracy was in the range of $88.33-101.25 \%$ (Table 2).

Stability. Most of the cases analysed are not carried out directly after collection of the biological samples; samples are usually processed and stored, so it is essential to maintain the relevant storage conditions in order to ensure that the obtained concentration results adequately reflect those directly after sampling [16]. The stability of

\section{Linearity Curve}

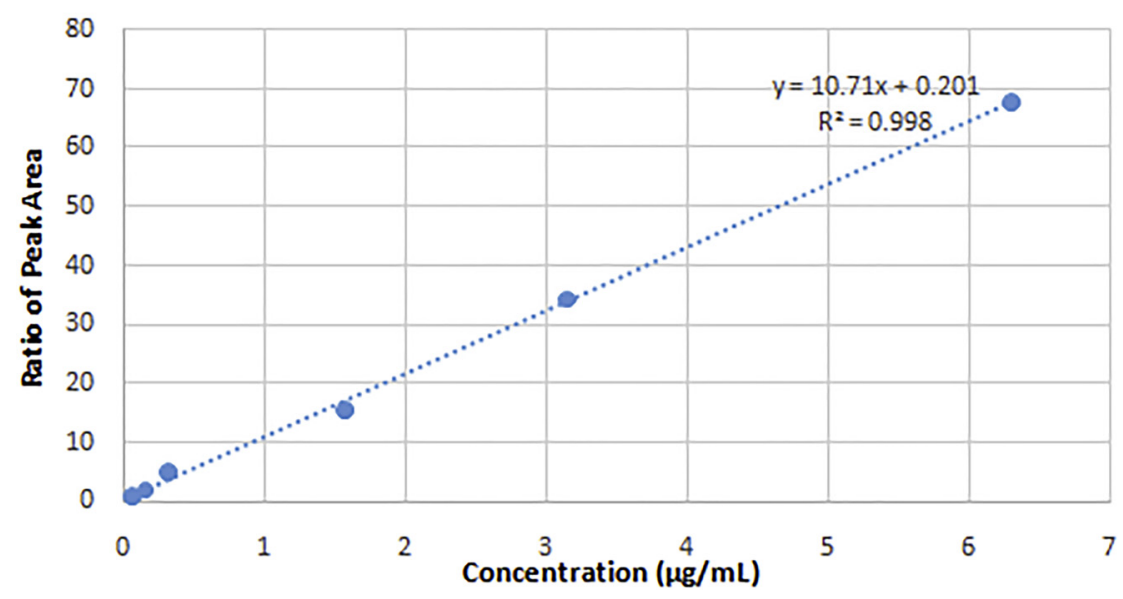

Fig. 3. Linearity curve of Esomeprazole using Pantoprazole as internal standard 
Table 2. The inter- and intra-day precision and accuracy of the method for the determination of Esomeprazole*

\begin{tabular}{|c|c|c|c|c|c|c|}
\hline \multicolumn{4}{|c|}{ Intra-day } & \multicolumn{3}{|c|}{ Inter-day } \\
\hline $\begin{array}{l}\text { Added conc. } \\
(\mu \mathrm{g} / \mathrm{mL})\end{array}$ & $\begin{array}{c}\text { Detected conc. (mean } \pm \mathrm{SD} \\
\mu \mathrm{g} / \mathrm{mL})\end{array}$ & $\begin{array}{c}\text { Mean accuracy } \\
(\%)\end{array}$ & $\begin{array}{l}\text { RSD } \\
(\%)\end{array}$ & $\begin{array}{c}\text { Detected conc. (mean } \pm \mathrm{SD} \\
\mu \mathrm{g} / \mathrm{mL})\end{array}$ & $\begin{array}{c}\text { Mean accuracy } \\
(\%)\end{array}$ & $\begin{array}{l}\mathrm{RSD} \\
(\%)\end{array}$ \\
\hline 0.06 & $0.058 \pm 0.003$ & 96.67 & 5.17 & $0.053 \pm 0.003$ & 88.33 & 5.66 \\
\hline 0.24 & $0.228 \pm 0.009$ & 95.00 & 3.95 & $0.220 \pm 0.010$ & 91.67 & 4.55 \\
\hline 2.40 & $2.419 \pm 0.092$ & 100.79 & 3.80 & $2.430 \pm 0.006$ & 101.25 & 0.25 \\
\hline 4.80 & $4.760 \pm 0.341$ & 99.17 & 7.16 & $4.77 \pm 0.173$ & 99.38 & 3.63 \\
\hline
\end{tabular}

${ }^{\star} n=5$ for intra-batch and $n=15$ for inter-batch

Table 3. Stability of Esomeprazole in human serum at different QC levels $(n=5)$

\begin{tabular}{|c|c|c|c|}
\hline $\begin{array}{l}\text { Declared } \\
\text { concentration }(\mu \mathrm{g} / \mathrm{mL})\end{array}$ & Condition & $\begin{array}{l}\text { Measured concentration } \\
\text { (Average } \pm \mathrm{SD} \mu \mathrm{g} / \mathrm{mL} \text { ) }\end{array}$ & $\begin{array}{l}\text { RSD } \\
(\%)\end{array}$ \\
\hline \multirow[t]{4}{*}{0.06} & Post-preparative stability (autosampler) after $24 \mathrm{~h}$ & $0.0 \backslash 59 \pm 0.005$ & 8.47 \\
\hline & Freeze-thaw stability after three cycles & $0.055 \pm 0.003$ & 5.45 \\
\hline & Long-term stability & $0.061 \pm 0.001$ & 1.63 \\
\hline & Short-term stability & $0.062 \pm 0.007$ & 11.29 \\
\hline \multirow[t]{4}{*}{0.24} & Post-preparative stability (autosampler) after $24 \mathrm{~h}$ & $0.245 \pm 0.0007$ & 0.29 \\
\hline & Freeze-thaw stability after three cycles & $0.238 \pm 0.003$ & 1.26 \\
\hline & Long-term stability & $0.241 \pm 0.004$ & 1.66 \\
\hline & Short-term stability & $0.238 \pm 0.007$ & 2.94 \\
\hline \multirow[t]{4}{*}{2.4} & Post-preparative stability (autosampler) after $24 \mathrm{~h}$ & $2.39 \pm 0.037$ & 1.55 \\
\hline & Freeze-thaw stability after three cycles & $2.38 \pm 0.041$ & 1.72 \\
\hline & Long-term stability & $2.35 \pm 0.044$ & 1.87 \\
\hline & Short-term stability & $2.43 \pm 0.077$ & 3.17 \\
\hline \multirow[t]{4}{*}{4.8} & Post-preparative stability (autosampler) after $24 \mathrm{~h}$ & $4.81 \pm 0.330$ & 6.86 \\
\hline & Freeze-thaw stability after three cycles & $4.78 \pm 0.270$ & 5.64 \\
\hline & Long-term stability & $4.77 \pm 0.310$ & 6.49 \\
\hline & Short-term stability & $4.82 \pm 0.190$ & 3.94 \\
\hline
\end{tabular}

Esomeprazole at $-20{ }^{\circ} \mathrm{C}$ for $24 \mathrm{~h}$, after three freeze thaw cycles, stability of Esomeprazole at $-20{ }^{\circ} \mathrm{C}$ for 15 days, and the stability of extracted plasma sample after preparation/autosampler stability are summarized in Table 3. It is clear that Esomeprazol was stable at both low and high concentrations under all tested conditions and time and no stability-related problems would be expected during routine analysis of the samples for pharmacokinetic, bioavailability, and bioequivalence study.

\section{CONCLUSION}

The method shows good and consistent recovery with accepted accuracy and precision as well as adequate sensitivity and selectivity. The main advantage of the method described here is its simplicity. To assure the quality of chromatogram and consequently the results, the critical points must be evaluated during the validation of bioanalytical methods. The method is suitable for plasma level monitoring of Esomeprazole in Bioequivalence study as well as in clinical laboratory.

Conflict of Interest: Authors have declared that they have nothing to disclose.

\section{ACKNOWLEDGEMENT}

The authors would like to thank the authority of Bangladesh Council of Scientific and Industrial Research (BCSIR) for providing necessary chemicals, reagents and laboratory facilities for this research. The authors are also thankful to the Beximco Pharmaceuticals Ltd. Bangladesh for providing working standard of Esomeprazole and Pantoprazole.

\section{REFERENCES}

1. Hassan-Alin, M.; Andersson, T.; Bredberg, E.; Röhss, K. Eur J Clin Pharmacol. 2000, 56, 665-670.

2. Islam, M. S.; Akter N.; Shohag, H.; Ullah, A.; Maruf, A. A.; Sultana, T. A.; Latif, A. H. M.; Hasnat, A. J Bioequiv Availab. 2011, 3(6), 139-143.

3. Jones, B.; Kenward, G. M. Design and Analysis of Cross-over Trials, 2nd ed.; Champman and Hall/CRC, 2003.

4. Nahar, K.; Joti, J. J.; Ullah, M. A.; Hasan. A.; Azad, M. A. K. Dhaka Univ J Pharm Sci. 2009, 8, 123-130.

5. Brunton, L. L.; Lazo, J. S.; Parker, K. L. Goodman \& Gilman's, The Pharmacological Basis of Therapeutics, 11th ed., McGraw-Hill Education, 2005.

6. Anderson, T.; Hassan-Alin, M.; Hasselgren, G.; Rohss, K.; Weidol, L. Clin. Pharmacokinet. 2001, 40(6), 411-426. 
7. Department of Health and Human Services, Food and Drug Administration. Bioanalytical Method Validation Guidance for Industry. 7500 Standish Place: Rockville, MD 20855, 2018, https:// www.fda.gov/files/drugs/published/Bioanalytical-Method-ValidationGuidance-for-Industry.pdf (Accessed January, 26, 2020).

8. Harahap, Y.; Baskara, A. E.; Harmita. J. Young Pharm. 2017, 9(Suppl. 1), s24-s28.

9. Cai, W.; Wang, Z.; Li, J.; Hu, J.; Zhong, J. Arzneimittelforschung 2011, 61(9), 502-505.

10. Chunduri, R. H. B.; Dannana, G. S. J. Pharma. Anal. 2016, 6, 190198.

11. Hultman, I.; Stenhoff, H.; Liljeblad, M. J. Chromatogr. B 2007, 848, 317-322.
12. Ahuja, S.; Michael, W. D. Hand Book of Pharmaceutical Analysis by HPLC, 6th ed.; Elsevier academic press: Amsterdam, 2005; pp 197206.

13. Rosing, H.; Man, W.Y.; Doyle, E.; Bult, A.; Beijnen, H. J. J. Liq. Chromatogr. Relat. Technol. 2000, 23, 329-354.

14. Nascimento, T. G.; Oliveria, E. J.; Macedo, R. O. J. Pharm. Biomed. Anal. 2005, 37, 777-783.

15. Polson, C.; Sarker, Pratibha.; Incledon, B.; Raguvaran, V.; Grant, R. J. Chromatogr. B 2003, 785, 263-275.

16. Shah, V. P.; Midha, K. K.; Findlay, J. W. A.; Hill, H. M.; Hulse, J. D.; McGilveray, I. J.; McKay, G.; Miller, K. J.; Patnaik, R. N.; Powell, M. L.; Tonelli, A.; Viswanathan, C. T.; Yacobi, A. Pharm. Res. 2000, 17, 1551-1557. 